\title{
Public Health Impact of Substance Use on Adolescent: A Snapshot of Yenagoa in Bayelsa State. Nigeria
}

\author{
Raimi Morufu Olalekan ${ }^{1 *}$ iD, Abdulraheem Aishat Funmilayo ${ }^{2}$, Major Iteimowei ${ }^{2}$, Ebikapaye \\ Okoyen $^{3}$, Bilewu Olaolu Oyinlola ${ }^{4}$ \\ ${ }^{1}$ Department of Community Medicine, Niger Delta University, Nigeria \\ ${ }^{2}$ Department of Sociology, Niger Delta University, Nigeria \\ ${ }^{3}$ Bayelsa State Ministry of Health, Nigeria \\ ${ }^{4}$ Department of Public and Environmental Health, Kwara State University, Nigeria \\ *Corresponding author: Raimi Morufu Olalekan, Department of Community Medicine, Environmental Health Unit, Faculty of \\ Clinical Sciences, Niger Delta University, Nigeria. \\ To Cite This Article: Raimi Morufu Olalekan, Abdulraheem Aishat Funmilayo, Major Iteimowei, Ebikapaye Okoyen, Bilewu Olaolu Oyinlola. \\ Public Health Impact of Substance Use on Adolescent: A Snapshot of Yenagoa in Bayelsa State. Nigeria. Am J Biomed Sci \& Res. 2019 - 4(3). \\ AJBSR.MS.ID.000796. DOI: 10.34297/AJBSR.2019.04.000796
}

Received: : May 14, 2019 | Published: July 29, 2019

\begin{abstract}
The Nigerian polarization of its society with an estimated population ranging from 198 to 210 million people, growing at the rate of $3.2 \%$ per annum, into a large rural sector and a small urban component could provide a basis for the rapid increase in the prevalence of substance use among adolescents, which has aroused public health concern and have been declared a national public health and social emergency with a threat multiplier. One in every five people in the world is an adolescent, regrettably four out of every 10 teenager's you meet on the street now abuse drugs and if unchecked, seven out of every 10 young persons on your street would become drug addicts by the year 2030 particularly in the major cities. Yet, many adolescents lose their lives during this adolescent period. However, the World Health Organization reported that an estimated 1.7 million adolescents die yearly mostly through accidents, suicide, violence, pregnancy related complications, substance abuse and high-risk behaviors or illnesses that are either preventable or treatable.
\end{abstract}

Adolescents suffer from a preponderance of health risk and behavioral problems. Admittedly, substance abuse is particularly problematic for this population and causes significant harm to their health and well-being. However, the teenage years are so volatile that parents should not worry about making much progress. Consequently, substance use affects developing brain by increasing the risk of addiction, mood disorders, lowered impulse control, increased risk for adverse consequences, confusion, cognitive impairment, and medical morbidity, which can contribute to hospitalizations and health care costs, as well as loss of independence and has been known to increase risky sexual activity, emphysema, lung cancer, heart disease, oral cancers, laryngeal carcinoma, and a number of other health issues in older age, decreased academic grades, and making poor decisions, that can be detrimental to the adolescents using or to others crime, militancy and violence behaviors etc. This article addresses the current trends and research related to the public health impact of substance use on adolescent. It is therefore vital for parent and societies to seize the opportunity of applying behavior modification, mind transformation and remodification therapy to young adults. Also, citizen advocacy should be intensified and encouraged on the health impact of substance use. It is also imperative that all stakeholders engage in concerted efforts to target both parents and adolescents in substance use control strategies.

Keywords: Substance Use; Adolescents; Public Health Emergency; Threat Multiplier; Militancy; Risky sexual activity; Yenagoa

\section{Introduction}

Yenagoa is the traditional home of the Ijaw people, the Ijaws form the majority of the town. Nigeria's fourth largest ethnic group after the Hausa, Yoruba and Igbo. English is the official language, but Epie/Atissa language, one of the Ijaw languages, is the major local language spoken in Yenagoa. Yenagoa is a great place to live, work, and raise a family and is one of the best small cities for business and careers. In fact, Yenagoa is one of the best city environments in which to raise children. However, this is fast eroding away due to the rise 
of cultism, crimes such as spontaneous shootings triggered by drug related poor mental health which has become a regular occurrence in our society such as you see it happen in places like Tombia, Swali, Agudama, Opolo and Azikoro etc. (Figure 1) and militancy behavior [1-3]. Yenagoa estimated population is 1,992,000 (2010 projected population) with a land mass of $11,007 \mathrm{Km} 2$. It has been a multiple whammy for adolescent in Nigeria, ever since the recent national survey about drug abuse which has been confirmed to be massive, meaning the rate at which young persons and adults are using psychoactive drug substance popularly referred to as "getting high" is more than the global average rate at $15 \%$ Nigeria's and $5.6 \%$ global. Of note, four (4) out of every ten (10) teenagers you meet on the street now abuse drugs and if this goes unchecked, seven (7) out of every ten (10) young persons on your street would become drug addicts by the year 2030 particularly in the major cities.

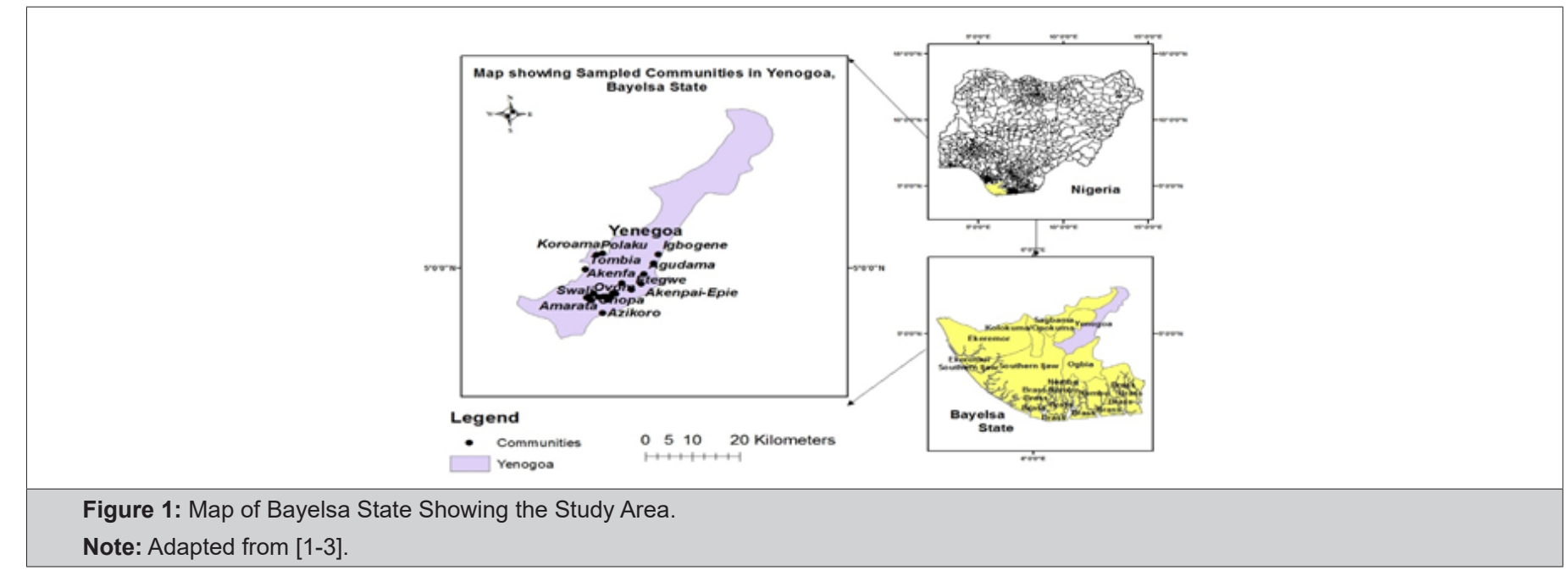

This was revealed by National Bureau of Statistics and Centre for Research and Information on Substance Abuse [2]. Unfortunately, substance abuse is known to be an important national, social and health problem in almost all countries in the world including Nigeria and have been declared a national public health emergency in the 21st century $[1,3,4]$. Although the rates of substance use are generally higher among younger people than older adults. However, to complicate matters, detecting substance-use can be especially challenging in the presence of multiple coexisting medical conditions. Usual social indicators of impaired function, such as difficulty at school, work, driving errors, or legal charges may be relevant for a person who is adolescent [1-3]. Yet unrecognized substance-use can cause substantial harm to adolescent in the form of an increased risk of cultism and militancy behavior has been witness in Yenagoa currently, confusion, cognitive impairment, and medical morbidity, which can contribute to hospitalizations and health care costs, as well as loss of independence. Large-scale epidemiologic studies conducted over the past 25 years have provided important information about rates of substance use [1,3], but longitudinal prospective studies, which would provide data on changing patterns of use, are lacking.

Previously, the prevalence tragedy of drug abuse was among adults and adolescent, but most alarming and worrisome now is the rate at which under-age teens are embracing drugs freely and unchecked. Worst still, young people are generating their mixtures, using conventional substances with unusual elements to create their own formula for severe drug intake which are often called "science students" for these practices [2]. This means that drug intake has graduated from the use of sedatives like cocaine, heroin and cannabis that we used to know to potent mixture of several drugs to attain fatal overdose. For example, a cocktail of drugs like codeine, tramadol, cannabis with juice or soft drink is called "gutter water". More crude is the smoking of lizard part, manure (dung), sniffing of petrol, glue, urine and sewage as inhalant. This is gradually eating deep into the fabric of our society like cancer. Actually, drug abuse is now part of a modern society, but very worrisome is the alarming rate at which youngsters are embracing hard substance [2].

Data from around the world suggests that substance use often starts between the ages of 14 and 15 [5,6]. There are numerous reasons given for this fact. However, the predominant reason seems to be that adolescence is a period of transition, in which individuals seem to be more impulsive, reckless and nonconforming than during other developmental stages of their lives [7]. Many adolescents engage in substance use activities, which they do perceive as risky, but are somehow acceptable within their peer groups. As a result, risk behaviors (including substance abuse) during the adolescent years are of major concern in Nigeria today. In Africa, the Nigerian experience is quite alarming. According to the National Drug Law Enforcement Agency [8], the use and abuse of drugs by adolescents have become one of the most disturbing health-related phenomena in Nigeria and other parts of the world. In Nigeria, most people use such drugs as coffee, colanut, and cigarettes for staying awake; or take alcohol and tobacco as a way of relaxation; or take painkillers like aspirin in reducing body pains. These are seen as licit drugs. However, the use or abuse of drugs such as cannabis or marijuana, cocaine, heroin and meth are seen as illicit in Nigeria. The widespread availability of these illicit drugs and frequency in its usage engenders its abuse [1-3].

According to the NDLEA 2014 report, drug use and abuse has been on the increase in Nigeria, despite efforts by anti-drug agencies in combating the menace. Statistics of arrest by geopolitical zones 
in Nigeria shows that North West, South West and North Central took the lead, while the South-South came fourth and has over $38 \%$ of the females arrested for drug offences (Table 1), even though Katsina, Kano and Bauchi States constitute the highest in terms of the statistics of arrest nationwide. In Nigeria, there has been an upsurge in the use and abuse of psychoactive substances. This upsurge has been characterized by an increase in the mental disorders, criminal acts such as spontaneous shootings triggered by drug related poor mental health and cult activities (as currently experience in yenagoa) in both the higher institutions of learning and also in secondary schools $[1,3,9]$. The high rate of road traffic accidents, increased violence and criminal behaviour are also partly attributed to alcohol and drug abuse [10]. Also, there is scanty data on patterns of drug abuse in specific groups in the community.

\begin{tabular}{|c|c|c|c|c|}
\hline \multicolumn{6}{|c|}{ Table 1: Arrests by Geopolitical Zones in Nigeria. } \\
\hline $\begin{array}{c}\text { Geopolitical } \\
\text { Zones }\end{array}$ & Males & Females & Total & \% \\
\hline North West & 2,214 & 47 & 2,261 & 25.62 \\
\hline South West & 1,604 & 78 & 1,682 & 19.06 \\
\hline North Central & 1,344 & 72 & 1,416 & 16.04 \\
\hline South South & 1,126 & 188 & 1,314 & 14.89 \\
\hline South East & 1,041 & 95 & 1,136 & 12.87 \\
\hline North East & 1,003 & 14 & 1,017 & 11.52 \\
\hline Total & 8,332 & 494 & 8,826 & 100 \\
\hline
\end{tabular}

Source: Adapted from NDLEA 2014 Annual report, p. 30.

Note: North West, South West and North Central took the lead, but over $38 \%$ of the females arrested came from the South-South.

Due to increasing urbanization of the country there is a tendency of changing patterns in illicit drug use therefore the need to constantly update information on the use of drugs among Nigerian adolescents. Linked to the above is a sharp increase in the cases of drug trafficking and abuse in the country and the most affected and vulnerable group has been identified as the youths between the ages of 16 and 45 years [11]. Recently, the rate at which young boys and girls are being introduced to dangerous narcotics calls for serious public concern. Now, young boys and girls display proudly their love for dangerous drugs and even get endorsements from some of our indigenous musicians thereby promoting this dangerous trend [13]. Even though the inflow of opioid is not limited to Nigeria alone, our rate has surpassed "normal" percentage. Last year, two major high-profile raids led to seizure of half a billion tablets of tramadol, the local pharmaceutical companies are also riddled with high level of corruption related to boosting of illicit supply of codeine-based cough syrups to these drug users. Often times, a teenager will drink complete bottle of cough syrup at once to get "high" [2].

Large-scale epidemiological studies have shown that about two thirds of late adolescents have admitted to using tobacco, over $80 \%$ have reported using alcohol, and half have admitted to experimenting with marijuana [12]. Overall, most adolescents admitted experimenting with an illicit substance rather than admitting substance-specific preference $[12,13]$ noted that adolescent experimentation with alcohol, marijuana, cigarettes, and other illicit substances increased through 18 years of age and then decreased as individuals got older. Illicit substance use by adolescents between 16 to 18 years of age has been commonly associated with other unhealthy and unproductive behavior [14]. Illicit substance use affects many regardless of race, religion, culture, or socio-economic status [14].

Substance use is a problem in society among adolescents. Adolescent substance use has declined from the mid-1990s, but other illicit substances, such as amphetamines and hallucinogens, has remained the same [15]. The constant interaction with peers exacerbates the easy availability of substances to the adolescents because there are more doors open to where they are able to obtain substances. In 2009, the Substance Abuse and Mental Health Services Administration (2010) conducted the National Survey on Drug Use and Health (NSDUH) to analyze the prevalence of substance use among adolescents age 12 to 18 . They found out that there was an increase in the number of adolescents using substances since 2002 [16]. There were 21.8 million estimated adolescents age 12 to 18 years who used illicit drugs in prior months before taking the survey, increasing from 20.1 million adolescent users in 2008 $[16,17]$. The survey's findings suggested that adolescents' negative attitudes about substances were beginning to change; for example, the negative attitude towards marijuana declined from $9 \%$ and $7 \%$ between 2008 and 2009 [16,17]. The results of the National Survey on Drug Use and Health suggested that adolescents were being misinformed about substances, which had changed the adolescents' perception of the risk in marijuana use $[16,17]$.

Research on preventing adolescent substance use has shown that adolescents rarely communicated with their parents about the issue $[15,18]$ suggested adolescents that were taught about the risks of substance use by their parents were $45 \%$ less likely to experiment with any type of substance. Risk factors of adolescent substance use have indicated which adolescents were more likely than others to use substances [19]. There are a number of risk factors that can contribute to an adolescent experimenting with a substance, such as lack of family cohesion, poor parent-adolescent relationship, and substance using friends, which are all risk factors associated with adolescent substance use [20]. Substance use in adolescents may not be specifically associated with just one risk factor, but with several risk factors that may lead to the adolescent experimenting with a substance [21].

\section{Adolescents' Substance Use}

Even though adolescents know the dangerous outcomes of using substances, there are still those who experiment, and sometimes, continue to use different substances. On average $45 \%$ of adults who initiated alcohol use as an adolescent became dependent on alcohol [22,23]. In 2007, an average of 39\% of eighth graders had used alcohol, $31 \%$ had used some form of tobacco, and $14 \%$ had used marijuana [22,24]. There is a wide array of consequences to substance use, such as becoming violent, increased high-risk sexual activity, decreased academic grades, and making poor decisions, that can be detrimental to the adolescents using or to others $[14,25]$. The use of substances can also decrease their judgment and 
it can consequently lead to detrimental health outcomes [14,25]. Adolescents' substance use can range from any substance including but not limited to cigarettes, alcohol, marijuana, and other illicit substances. When adolescents begin to use one substance there is a likelihood that they will progress to other substances [13,26,27]. When adolescents go from one substance to another it is referred to as a gateway substance. In describing the gateway model, [26] noted that "substance use progresses from no substance use to beer or wine, then to cigarettes or hard liquor, to marijuana, and eventually to other illicit substances" (pg. 78). For example, adolescents are likely to use cigarettes and then progress on to marijuana and alcohol [27]. According to this theory, adolescents will experiment with one substance before they begin to progress to the use of other substances $[13,26]$.

\section{Marijuana Use}

Marijuana is a popular illicit substance used by millions of people every day, constituting $75 \%$ of the illicit substances used in the United States [26,28-31]. Additionally, the earlier one is given the opportunity to experiment with the substance, the likelihood of long-term use increases [29,32-36]. Additionally, the earlier an adolescent begins to use a substance, the frequency of the use increases and the likelihood of progressing to heavier use tends to increase [35,37-40]. The use of marijuana is often the first use of an illicit substance and can become the gateway to the use of other substances, such as heroin, crack, and cocaine [28,29,32,34,41,42].

Marijuana is an addictive substance that can produce adverse mental, emotional, and behavioral changes, such as lung harm, impaired short-term memory, and impaired judgment $[22,29,43,44]$. There have been links between marijuana use and severe depression, behavioral problems at home and school, increased aggression, and declining academic achievement [41,4547]. Another association with marijuana use is sensation seeking or the engagement in risky behavior $[2,46]$. The adolescent's association with peers who also use marijuana increases the chance that he or she will engage in sensation seeking $[2,46,48]$. Marijuana is easily accessible for adolescents. Studies have found that $20 \%$ of eighth graders, $69 \%$ of 10 th graders, and $81 \%$ of 12 th graders reported they did not have a problem getting the substance $[29,39,49]$. The easy accessibility of marijuana has contributed to the high numbers of adolescents who are using.

In 2002, there were an estimated 2.6 million Americans using marijuana and around two thirds of those were adolescents $[29,50]$. Additionally, the use of marijuana among adolescents has begun to increase since 2006 following a decline for several years prior [51], and it was found in 2006 that $15.7 \%$ of eighth graders had tried marijuana at least once, $14.2 \%$ of 10 th graders were frequent users, and $42.3 \%$ of 12 th graders had experimented with marijuana once and an estimated 18\% were frequent users [50]. From the 2009 Monitoring the Future Survey, [49] reported that $12 \%$ of eighth graders, $27 \%$ of 10 th graders, and one third of $12^{\text {th }}$ graders were using marijuana in 2009. According to The NSDUH Report [52], as the age of the adolescents increased, marijuana use increased, and the perception of risk decreased, meaning that those adolescents who perceived the risk of marijuana use were less likely to use marijuana versus those who did not perceive great risk [20] conducted a study to determine if there was a relationship between adolescent marijuana use and its continuation into young adulthood [20] found that those adolescents who used marijuana were 1.83 times more likely to progress to other illicit substance use.

The relationship between adolescent marijuana use and continued young adult illicit substance use was mediated by the environment the adolescents were associated with; in other words, marijuana use could be the gateway substance to other illicit substance use but only through social mechanisms. Also, siblings who used marijuana were two times more likely of continuing on to other illicit substance use in young adulthood. This can be based on the family's background, which can be a determining factor in the progression towards other illicit substance use [20]. Qualitative studies have also shown that older persons who use marijuana often report using it for relaxation or social recreation [53,54], but it is also frequently seen as a safer alternative to prescription medications for chronic pain [55]. Little is known about the longterm consequences of marijuana use in adolescent, but short-term use in all age groups has been correlated with impairment in shortterm memory, coordination, and driving, as well as increased risks of injury, paranoia, and psychosis. The chemical composition of marijuana is complex, and its effects on brain function and other physiological processes in younger and older adults have not been sufficiently studied.

Both adolescents and older adults with coexisting chronic medical conditions who use marijuana may be at risk for cognitive changes, falls, and interactions with prescription medications. Given that more states are making marijuana legal for medicinal or recreational use, marijuana use among adolescent is likely to increase. Research is needed to understand the effects of longterm cannabis use on adolescent. The NESARC showed that the prevalence of marijuana use among adolescent increased between 2002-2003 and 2012-2013 [22], Older marijuana users are likely to have started use in their teen years and may have long-term or frequent use. In addition, the proportion of admissions for alcohol use alone decreased, whereas admissions for use of illicit drugs and for use of drugs in combination with alcohol nearly doubled [1,3].

\section{Tobacco Use}

Adolescence is a critical period when most people will try tobacco products and tobacco use has been a leading cause of preventable death in the United States, yet many adolescents initiate the use [2,50,56-59]. Adolescents who begin use of tobacco early have a greater risk of being affected with numerous health problems such as emphysema, lung cancer, heart disease, oral cancers, laryngeal carcinoma, and a number of other health issues in older age [26,60]. There are an estimated 438,000 people who die from tobacco-related illnesses yearly [61,60]. Additionally, there are an estimated 3,000 adolescents who experiment with smoking every day, and approximately one third of them will become regular smokers [26]. It has also been shown that when adolescents begin 
to smoke cigarettes, they are 14 times more likely to try marijuana [25]. Adolescents may try smoking at different points in their lives.

[49] noted that $44 \%$ of adolescents experimented with cigarettes by 12 th grade and $20 \%$ of them were current cigarette smokers. There were $22 \%$ of eighth graders and $46 \%$ of 12 th graders who admitted having tried smoking $[51,62]$. By the time adolescents entered into the 12th grade 1 out of every 4 , of those adolescents would have tried smoking $[51,62,63]$ noted that frequent smokers had higher use of other substances, lower school performance, and increased chances of being a frequent smoker. Between 2002 and 2008 there was a decline in smoking from 15.2 $\%$ to $11.4 \%$ according to The NSDUH Report [17]. For example, there were only about $2.7 \%$ of eighth graders and $11.2 \%$ of 12 th graders who reported that they were daily users, down from $10.4 \%$ of eighth graders in 1996 and $24.6 \%$ of 12th graders in 1997 [17]. There has been growing concern for smokeless tobacco and other tobacco use, such as cigar use. Researchers claimed that smokeless tobacco use was the gateway to smoking and would lead to an increase in adolescent smoking [21,64].

Other researchers argued that smokeless tobacco use was a behavior associated with smoking and did not cause one to smoke [2]. Among $10^{\text {th }}$ graders surveyed, their use of smokeless tobacco increased by $6.5 \%$ (NIDA, 2009). The NSDUH Report indicated that in 2008 cigar use was down by $3.8 \%$ when compared to 2002 to 2004 , but it was equal to the rates found in 2005 to 2007 [17]. Smokeless and pipe tobacco remained consistent between 2002 and 2008 with $2.2 \%$ of smokeless tobacco use and $0.7 \%$ of pipe tobacco use [17]. Researchers have been trying to find ways to reduce the number of adolescent smokers and to identify factors for why adolescents begin to smoke. When an adolescent begins to smoke, it is either because he or she has a parent who smokes or peers who smoke [62,65-67]. In a study conducted by Gilman SE [68], the authors examined parental smoking history to determine if there was a relationship with smoking initiation of adolescents. The 564 participants of the study, ages 12 to 17, were enrolled into the New England Family Study along with one of their parents between 2001 and 2004. The parents were asked about their history of smoking, age they began smoking, how many times they attempted to quit, and periods when they did not smoke at all.

The adolescents were asked about their exposure to their parents' smoking, age when they tried smoking, and about the reactions to the smoking whether positive or negative. Gilman SE [68] found that when the parents smoked there was a high risk that the adolescent would begin to smoke. If both parents smoked and the duration of the adolescent exposure to the smoking increased, the chances that they adolescent would smoke increased even more, therefore showing a dose-response relationship between the parents' smoking habits and the adolescent's smoking habits. Adolescents of parents who ceased smoking were less likely to smoke just as adolescents whose parents never smoked. Pozzato $\mathrm{G}$ [62] examined the correlation between whom the adolescent interacted with and the effects on subsequent adolescent tobacco use. When adolescents associated with peers who used tobacco, it was a predictor of tobacco use with the group. Pozzato G [62] only relied on those adolescents from the 9th to the 11th grades who had smoking information on their responses $(N=6696)$. Pozzato G [62] found that if an adolescent had friends who smoked and if the number of friends increased who smoked, there was a higher prediction that the adolescent would begin to smoke. If the adolescent associated with a group of peers who smoked and his or her group was linked with another group who smoked, it would consequently lead to increased risk of the adolescent smoking more. Associating with a group of peers who smoke increases the chances of the adolescent becoming dependent on nicotine and developing health problems later in life.

Idowu A [69] found that students smoke and use drugs at the instance of friends/peers, parents and television/radio advertisements. Oladele $[2,70,71]$ showed that adolescents were very susceptible to the influence of their peers. [59] asserted that socially, a drug abuser is always pre-occupied with how to obtain drug of choice and crave for the substance. Kobiowu SV [72] study revealed that the academic pursuits of those undergraduates who engages in drug misuse is not unduly jeopardized and that the abusers do not socialize extraordinarily, contrary to seemingly popular expectation.

\section{Alcohol Use}

Alcohol is regarded as the most widely abused substance and early alcohol use is the leading factor in heavy and abusive use of alcohol, and it has been the third leading cause of death within the United States [73]. Although alcohol consumption generally decreases with advancing age [6], demographic trends show an increase in alcohol-use among adolescents in the United States including Nigeria $[2,74,75]$, adolescent tends to consume alcohol at a level above the limit recommended by the National Institute on Alcohol Abuse and Alcoholism (NIAAA). When coexisting medical conditions such as hypertension and diabetes are factored in, $53.3 \%$ of drinkers have potentially harmful levels of consumption. The 2013 National Survey on Drug Use and Health showed heavy drinking (defined as drinking five or more drinks on the same occasion on each of 5 or more days in the past 30 days) and binge drinking (defined as drinking five or more drinks on the same occasion on at least 1 day in the past 30 days) among $14.1 \%$ of persons [76] Studies has shown that men are at higher risk than women for harmful consumption, but prevalence rates for drinking are increasing faster among women than among men [2].

In the United States alcohol is one of the most accepted and abused substances [3,26] and adolescents use has increased between the ages of 16 and 20 [77,78]. Of all substances that adolescents may choose to use, alcohol has been the substance of choice for most adolescents [38,58,79]. For example, [80] found that in 2008 there was an average of 10.1 million under-aged drinkers in the United States. Of those drinkers, $17.4 \%$ were binge drinkers and $5.5 \%$ were heavy drinkers. The Monitoring the Future study found that $15 \%$ of eighth graders, $30 \%$ of 10 th graders, and $44 \%$ of 12 th graders in 2009 reported having used alcohol recently [51]. Without proper education of the risks of alcohol, the percentage of adolescents using alcohol may increase. 
If an adolescent begins to use alcohol, there are increased chances of more problems within and outside of his or her home life, such as family problems, stressful events, and behavioral problems [3,58,81-83]. Additionally, using alcohol in an abusive manner increases the chance of vehicular accidents, contracting sexually transmitted diseases from high risk sexual activity, and an increase use and abuse of illegal substances $[32,58,82,83]$ conducted a study to find the prevalence of the alcohol types that were used among adolescent in eighth and 10th graders. Patrick ME [83] found that 1 out 10 eighth graders and 1 out of 510 th graders had participated in binge drinking within the last 2 weeks prior to the study. Alcohol use within the previous year was reported by $24.1 \%$ of the eighth graders and $35.9 \%$ of the 10 th graders in the study. Heavy alcohol use remained high among those adolescents in the 10th grade. If the adolescent used another substance there was a high correlation of alcohol use and if there were peers who participated in excessive alcohol use there was a greater impact of alcohol use [83].

Research has shown that one in every 13 individuals throughout the world abuse alcohol or are in fact alcoholics [19,84] reported that drinking alcohol is a significant problem for $10-20 \%$ of the adolescent population. Furthermore, in the age range of 13-18 years in the United States there are approximately three million problem drinkers [19]. In a study done by SAMHSA, it was found that approximately 7-8\% of young adolescents (12-13 years); 20$21 \%$ of adolescents (13-15 years); and $33 \%$ of older adolescents (16-18 years) reported the use of alcohol within the preceding month. This suggests that initiation into alcohol use starts at a very young age and it progresses with age. About $10 \%$ of women and $20 \%$ of men have met the diagnostic criteria for alcohol abuse sometime during their lives and males tend to binge drink more than females [85].

However, international research shows that although males tend to drink more than females, the gap between male and female alcohol consumption is narrowing [86]. In terms of culture, past research suggests that Whites drink more than other cultural groups, and that in terms of alcohol abuse there are no statistically significant differences by culture [86]. In older adults as compared with their younger counterparts, impairment and an increase in the risk of falls occur at lower levels of alcohol consumption, but there is no evidence that liver metabolism of alcohol is significantly changed with aging $[62,87]$. The long-term health complications of alcohol use in older people are the same as those in younger people. However, alcohol use has been found to increase the risk of hospitalization among adults [88]. Those with alcohol-use and multiple chronic health conditions are more likely to report depressive symptoms than are adults of a similar age who do not have alcohol-use disorder [89].

The increased risk of a harmful interaction between alcohol and prescribed medications is of clinical importance, and adolescent often lack knowledge of the risks of such interactions $[90,91]$. Even close family members may miss problematic consumption by an elderly relative whose drinking is occurring at home. Coexisting medical conditions, including cognitive impairment, can obscure signs of harmful use, which may be mistaken for anxiety, depression, or complications of current medical treatments. Results from the 2003 National Survey on Drug Use and Health conducted by SAMHSA in the USA serve as an effective way to highlight the epidemiology of alcohol use as their findings are consistent with the literature put forward. The table points to gender, cultural and age group differences with regard to alcohol use (Table 2). The results of this study confirm that alcohol use tends to increase with age. Males were more likely than females to report current use of alcohol, binge drinking and heavy drinking however, within the 12-17year age group the gap between the two was very narrow. Cultural differences were also evident as Asian and Black youths had the smallest rates of alcohol use. White youths had the greatest rate of use.

Table 2: Results from SAMHSA's National Survey on Drug Use and Health.

\begin{tabular}{|c|c|c|c|}
\hline 2003 survey & $\begin{array}{c}\text { \% who cur- } \\
\text { rently drink }\end{array}$ & $\begin{array}{c}\text { \% who are } \\
\text { binge drink- } \\
\text { ers }\end{array}$ & $\begin{array}{c}\text { \% who are } \\
\text { heavy Drink- } \\
\text { ers }\end{array}$ \\
\hline \multicolumn{4}{|c|}{ Age groups } \\
\hline Youths aged 12-13 & 4.5 & 1.6 & 0.1 \\
\hline Youths aged 14-15 & 17 & 9.4 & 2.2 \\
\hline Youths aged 16-17 & 31.8 & 21.2 & 5.5 \\
\hline $\begin{array}{c}\text { All youths aged } \\
\text { 12-17 }\end{array}$ & 17.7 & 10.6 & 2.6 \\
\hline \multicolumn{4}{|c|}{ Gender (aged 12-17) } \\
\hline Male & 17.1 & 11.1 & 2.9 \\
\hline Female & 18.3 & 10.1 & 2.3 \\
\hline \multicolumn{4}{|c|}{ Race/ethnicity (aged 12-17) } \\
\hline White & 20.5 & 12.8 & 3.5 \\
\hline Black/African & 10.1 & 4.6 & 0.5 \\
\hline American & 16.3 & 12.4 & 1.7 \\
\hline American Indian/ \\
Alaska Native
\end{tabular}

In Nigeria, research efforts into the problem of drug and alcohol abuse started in the late 1950s. Since then, shifts in the pattern and types of drugs abused in the country have been reported and increasing female involvement and multiple drug use pattern have also been noticed [92]. Factors found to contribute to this changing trend include urbanization, industrialization and increased exposure to western lifestyle, peer pressure, deficient family support and increasing advertisement of such in the mass media, among others $[52,92,93]$. It is obvious, through scholarly studies, that research efforts into alcohol and related issues in Nigeria have increased in recent time.

\section{Other Illicit Substance Use}

Illicit drugs are most widely used by individuals aged 18-26 and use is lowest among individuals 50 years and older. Males are twice as likely to use illicit drugs than their female counterparts. 
Substance use does not only include the use of alcohol, tobacco, and marijuana. There are numerous other illicit substances that adolescents may try. Alcohol, tobacco, and marijuana are considered the gateway substances to the use of cocaine, crack, heroin, etc. [94]. With early initiated use of marijuana before the age of 15 years, there is a greater chance of other illicit substance use and dependency [94]. Adolescents who begin to use substances like heroin and cocaine believe they are at a minimal risk of the consequences of using these substances [26]. According to Graydanus DE [26] by the completion of high school an average of $50 \%$ of adolescents will have tried other illicit substances. In 2009, adolescents' use of hallucinogens and LSD has decreased from 5.9\% to $4.7 \%$ and from $2.7 \%$ to $1.9 \%$ [44]. As of 2009 there has been an increase in illicit substances being used, such as Ecstasy and methamphetamine $[16,95]$. It was noted that there was an increase of $60 \%$ of adolescents who began to use methamphetamine and an estimated 760,000 adolescents who began to use ecstasy $[16,95]$.

Oshikoya KA [59] examined the perception of drug abuse amongst Nigerian undergraduates living off-campus, using the Lagos State University, Ojo, as a case study, the study found a chronic use of drugs by students, but little addiction or abuse. The most commonly drugs of abuse include marijuana, alcohol and coffee. The study also revealed the poor attitudes of the undergraduates to drug addicts even after rehabilitation, and thus concluded that the awareness, knowledge, practices and attitudes of Nigerian undergraduates towards drug abuse is very poor. Finally, the study recommended considerably more research in order to develop effective prevention strategy that combines school-based interventions with those affecting the family, social institutions and the larger community. Students, especially those in secondary school tend to see the drug user as one who is tough, bold and strong. Many youngsters have been known to use drugs at the instance of peers, elders or siblings. Students who usually feel inadequate have been known to use drugs to achieve social acceptance. Esen AJA [96] stated that Nigerian secondary school adolescents under the influence of Indian hemp shed all inhibitions and produce behaviour that is inconsistent with school discipline.

He went further to observe that the increasing incidence of drug abuse among secondary school students is a contributory factor in the ugly confrontation between school administration and students. The problem of drug abuse knows no boundaries as social class, as it impedes the development of any society as it is a threat to life, health, dignity and prosperity of all individuals $[1,3,64,70,97,98]$, in their research on the effect of drug abuse on educational performance of some adolescent drug abusers in Ibadan, found that the misuse of marijuana had reached an epidemic level in the present Nigeria society, and that drug abuse could lead to reduce academic achievement or even halt one's entire academic process. Some studies $[1,3,99,100]$ dwelled extensively on reasons students use drugs include success in examination, social acceptance and initiation of peers. Olatunde A [101] states that Nigerian adolescents take drugs such as amphetamines and pro-plus as aid for success in examination and postulates that those who take drugs as aid for studies toward examinations are those with poor academic records, a history of instability and family/social problems, while others, he commended; use rugs to increase their self-confidence, heighten pleasure, cope with feelings of depression and inadequacy and to facilitate communication [59].

Studies by $[1,37,102-104]$ exhibit a plethora of purposes for which students use drug. The list includes curiosity, boldness, friends-do-it, enjoyment of social gathering, academic pressure, sound sleep, sexual-prowess, and performance in sports. Drug abuse is a very serious problem among school adolescents, and which has slowly made the average Nigerian student to be maimed, sentenced to a life of delinquency, insanity, street walking and premature death. Atoyebi OA [105] studied pattern of substance abuse among senior secondary school students in a southwestern Nigerian city, using 450 students. This cross-sectional study reveals that the most commonly abused substances were analgesics, cannabis, tobacco, alcohol and sedatives; and that majority of respondents (87.4\%) had positive attitude towards substance abuse and would do everything to ensure they discourage a friend from using such substances.

Furthermore, SAMHSA (2001) found that $4 \%$ of the young adolescents (12-13 years), $11 \%$ of the age group 14-15 years and $16 \%$ of the older adolescents (16-18 years) reported the use of marijuana (cannabis), cocaine, crack, inhalants, hallucinogens or heroin in the preceding month (SAMHSA, 2001). American statistics show that marijuana remains the most common illicit drug used by adolescents with the level of other illicit substances significantly lower [106]. There has been continuous increase of prescription substances and cough syrup use among adolescents [107]. For example, 1 in 10 12th graders admitted to nonmedical use of Vicodin, and 1 in 20 admitted non-medical use of Oxycontin [107]. There are an estimated 5.3 million adolescents aged 12 years and older who abuse prescription pain relievers daily [16,95]. The adolescents obtain these substances from family members or friends because there is easy access to the prescriptions that are not being unused and or secured in medicine cabinets within adolescents' home $[16,95,108]$. The Monitoring the Future Study found that $58.2 \%$ of adolescents who admitted to using a prescription painkiller obtained the medications from a relative or friend for free $[37,108]$.

Substance abuse in adolescents can be associated with other high-risk behaviours such as drinking and driving, participation in devious peer groups, interpersonal violence, and destruction of private property [109]. Substance use is also related to decreased inhibitions and thus an increased probability of engaging in high risk sexual behaviours, placing the adolescent at risk for both unwanted pregnancies and sexually transmitted diseases including HIV [1]. Substance abuse can also contribute to an increased risk for suicide ideation and behaviour and it increases the probability for psychiatric disorders, including conduct, mood and anxiety disorders. Furthermore, according to SACENDU reports, adolescent substance abuse has been associated with academic difficulties, declining grades, absenteeism, truancy and school dropout [1]. 
Thus, although substance abuse alone is related to some serious behavioural problems, the effects associated with it are also of a serious and concerning nature. Another important finding is that certain substances have been shown to predate entry into other substance abuse and as such, most substance abusers do not limit themselves to one particular substance but typically use two or more substances [110].

\section{Substance Use among adolescents in Yenagoa}

Studies by Abdulraheem A FO \& Funmilayo AA [1,3] shows that the most frequently used substance among adolescents in Yenagoa Local Government is alcohol, cigarettes are in the second place, marijuana in the third and cocaine (as the only drug with significant frequency of consumption) in the fourth place (Figure 1). According to the study results, $33.2 \%$ of students have consumed alcohol at least once in their life. The research findings show that alcohol is the most commonly used substance among adolescents in Yenagoa Local Government and this figure is in line with international research. This is consistent with recent international and local statistics that revealed that alcohol is still regarded as the most popular used substance $[1,3,84]$. In this study, $33.2 \%$ of the sample reportedly drank alcohol within the past 30 days and a further $14 \%$ reportedly binged (drinked) within the past 30 days period. In a recent SAMHSA study, approximately $25 \%$ of adolescents reportedly used alcohol within a 30 days period and thus the results are extremely consistent.

Other drug use was reported at (26.8\%) cigarette, $(24.2 \%)$ marijuana and $(13.8 \%)$ cocaine which is fairly consistent with SAMHSA findings in 2001 which reported that $10 \%$ of adolescents reportedly used marijuana, cocaine, crack, inhalants, hallucinogens or heroin. Past, research however, suggests that cannabis would be the illicit substance most likely to be used by high school attending adolescents. In this regard, drug use percentage would probably be largely accounted for by cannabis [111]. This is concerning because while the so called "Gateway Theory" - the idea that experimenting with "soft" drugs like cannabis will inevitably lead to heroin addiction and squalid death - has been discredited, there is evidence to show that adolescents who start drinking, smoking and using cannabis at an earlier age are more likely to take "hard" drugs than those who start later [86]. As the literature highlights, adolescents involved with any form of substance use are more likely to be involved in other risky behaviours has currently being experienced in Yenagoa and its environs; they are more likely to have academic problems; and they are more likely to initiate use in other substances. As a result, the $33.2 \%$ of adolescents who reported used alcohol and the $26.8 \%$ who use cigarettes, $(24.2 \%)$ marijuana and (13.8\%) cocaine respectively, are a cause of huge concern. It was hypothesised that belonging to different race, groups, age and gender have an effect on one's level of substance abuse.

The results of this study in terms of substance use patterns are consistent with the literature discussed in chapters two and three. The finding that $33.2 \%, 26.8 \%, 24.2 \%$ and $13.8 \%$ of the sample are drinking and using drugs respectively is one of grave concern in light of the fact that all of the respondents are 20 years or below and that drinking, and drug use are illegal for these age groups. What is also of concern is that although majority of the substance abusers use alcohol, it is known that alcohol use predates entry into many other forms of substance use [19]. Furthermore, studies have found that among adolescents enrolled in substance abuse treatment programmes, $96 \%$ are polydrug users, and that $96 \%$ of the polydrug users also use alcohol [85]. As such it should be realised that the $33.2 \%$ of alcohol abusing adolescents are possibly on the road to more dangerous and illicit drug use.

The Federal Ministry of Health has recommended no alcohol consumption below age 15 years [2]. Health implications can be short term or long term and can involve both acute and chronic adverse effects. Health implications for alcohol use include liver disease, cardiovascular disease, cancer, violence, and road traffic accidents. Over a quarter of deaths of 16-24-year olds have been attributed to alcohol consumption [49]. Comparatively, a study in Canada showed some similarities in the findings of this study in terms of the high prevalence of alcohol use. The top five substances used by youth according to the 2010 Canadian Alcohol and Drug Use Monitoring Survey (CADUMS) were alcohol (71.5\%), marijuana (25.1\%), hallucinogens (4.6\%), ecstasy (3.8\%) and cocaine $(2.7 \%)$ (Health Canada. (2010). While another study in Lagos still showed a lower alcohol prevalence of $29.1 \%$ [112], in relation to this study, another one in Minna revealed even much lower prevalence of thirty-four respondents (17\%) abusing alcohol and forty-five respondents (22.5\%) cigarette [113]. Also, in a study of 3,870 students from 20 school boards in Ontario, Canada on drug use, it was found that a total of 58.8\% students use alcohol, $27.9 \%$ use cigarettes and $22.7 \%$ use cannabis. Although the proportions are higher compared with this present study, the order of common use agrees with the findings.

Having looked at the results of a number of surveys and compared with that of this study, it can be inferred that the common substances often abused by the youths are cigarettes, cocaine, marijuana and alcohol. The order of occurrence varies with respect to the community studied. The reasons for the lower frequency in cigarette smoking in this study could be attributable to the upsurge of public education and warnings from Ministry of Health "that smokers are liable to die young" about the effects of tobacco in recent years coupled with the involvement of the youths in the celebration of 'No Tobacco Days' nationwide, though infrequent. The level of use of alcohol is probably due to the social permissiveness in alcohol use. It is a drug with important social roles and is therefore acceptable. Consequently, there are few laws governing its usage and restriction within the population. Besides, brewing companies go at length to produce and advertise specific alcoholic beverages aimed at wooing the youth into alcohol use. No specific reason could be attributed to the very low frequency in cocaine use in this study. The result was surprising to investigators since there are heightened speculations that more youth are abusing cocaine. It is strongly felt that respondents probably were not convinced that divulging such information to the research team was safe (Figure 2). 


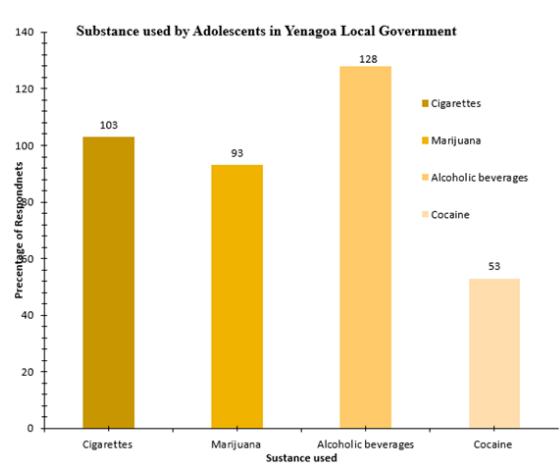

Figure 2: Bar chart showing substance used by adolescents in Yenagoa Local Government $[1,3]$.

\section{Risk Factors of Adolescent Substance Use}

Research has sought to determine if one risk factor outweighs other risk factors in determining why adolescents use substances. There are many factors that can influence the reasons adolescents use substances, such as family and peer relationships [1,3]. The relationships with family and peers can determine substance use for reasons like peer pressure, family problems, and lack of parental monitoring $[1,3,114]$. During younger adolescence parental influence is a strong determinant of substance use, whereas, in latter adolescence peer influence is greater [27,115-117]. The bonding within these two groups is the deciding factor in an adolescent's use of a substance. Family and peer relationships are constantly working simultaneously in influencing the adolescent's attitudes $[2,118]$. There are numerous reasons why an adolescent may begin to use a substance, for instance, trying to fit in with peers or seeing someone within their family using a substance [118]. Time with peers may be frequent and held in higher accord by adolescents, making peer influence more powerful, but family influences also play and important factor in shaping the adolescent's attitude towards substance use $[27,118]$.

\section{Peer Risk Factors}

Peers are thought to have the greatest influence over other adolescents because they spend a majority of time with one another. Peers can influence the thoughts and actions of other adolescents who try to fit in. When there is a lack of cohesiveness within the family adolescents are more susceptible to peer influences $[1,3,114,119]$. During socialization, peers can either encourage or discourage substance use, and this is based on the selection of friends the adolescent has chosen to socialize with and also the norms of the group [117]. When adolescents associate with those who engage in deviant acts, both the peer socialization and selection have a high impact on the adolescent's choice to use a substance $[1,2,3,117,120]$.

During adolescence there is a period of wanting more independence, increased autonomy, and more connection with their peers, thus increasing the chances of the adolescent engaging in substance use [114]. A peer relationship is important to the development of social skills outside of the family matrix and teaches adolescents how to interact effectively with others [115-117]. Based on the parent-adolescent relationship this can determine the types of friends the adolescent will select to interact with. Brook JS [120] notes that positive parent influence and monitoring builds the foundation for adolescents to choose to affiliate themselves with non-substance using or substance using peers. When an adolescent begins to engage with peers who use a substance the individual is more likely to engage in substance use [114]. If adolescents interact with peers who make the substances available, make the use acceptable, and encourages use, the likelihood of use typically increases [117]. It has been shown that adolescent's alcohol and cigarette use has been the result of strong peer influence and once peer influence becomes stronger than the family influence there is an increased chance for continual use [27,121]. Even though peer relationships may have a strong influence on adolescent substance use, family relationships can moderate the choices the adolescent will make $[120,122]$ conducted a study examining peer influences on adolescent's substance use.

The sample size in the study consisted of 1,040 adolescents in the sixth and seventh grade from eight schools in Kansas City, Missouri. [122] utilized the growth curve model (GCM) to analyze the relationship of adolescent substance use to peer use influences beginning in middle school and continuing through high school. It was paired with the Mid-Western Prevention Project (MPP) that based its study on the Integrative Transactional Theory (ITT) that suggests that peer influence on adolescent substance use is a combination of modelling and perceived norms [122] hypothesized that peer influences and substance use would grow in middle and high school but would be greater in high school; when peer influences grow it would predict the growth in substance use; and peer influences would affect the level of adolescent substance use [122] results found that as peer use and perceived norms increase, the more likely the adolescent would participate in substance use as well. For example, perceived peer use of cigarettes in middle school influenced the use of cigarettes in high school.

\section{Familial Risk Factors}

Family and adolescent relationships are important in determining what decisions adolescent will make regarding substance use. In family settings adolescents form their identity and receive nurturing and safety. It is also during adolescence that the family has to renegotiate boundaries to help in eliminating problems [123]. The family interactional theory argues that the 
stronger the attachment is between parent and adolescent, the less likely the adolescent will be involved in substance use [120]. There are many factors a family will encounter that play a role as to why an adolescent may choose to try substances. These may include: "family conflict and domestic violence; lack of family cohesion; social isolation of family; heightened sanctions regarding substance use; sibling rivalry; poor adolescent supervision and discipline practices; parental education level; unrealistic developmental expectations; and characteristics such as race and ethnicity" [123]. Adolescents begin to want to branch away from their families and become their own person. The more adolescents begin to branch off from the rest of their family and adopt other views outside of their parents' the more likely they are to use a substance [114].

The family is an important resource where adolescents can build their attitude about substance use because the family is the social group that adolescents will have the longest interaction over a period of time [27,121]. Family conflict is one determinant of adolescent substance use. Parental arguments or conflict with parents are factors for adolescent substance use [114]. The more adolescents are involved in conflicts within the household, the more emotional distress is placed on the adolescent [114]. When the family is classified as dysfunctional adolescents may engage in substance use to escape the problems in the home [21,27]. If there is conflict between adolescents and parents, the adolescent may begin to interact with peers who have acceptable views towards substance use [123]. If the adolescent lives in a household where substance use is relevant, the likelihood of adolescent's substance use increases $[47,115,120]$.

Bahr S J [121] found that $82 \%$ of parents who use alcohol had adolescents who used alcohol [47] found that if both parents engaged in some form of substance use there was a greater chance of adolescent substance use. As such, when adolescents engage in the same acts as someone in the household, they are modelling the behavior of a family member $[19,47]$. Sibling substance use is also an important factor because this is one of the strongest interactions the adolescent will have of all relationships due the "length and intensity" of the relationship [123]. Siblings learn different things from one another, therefore, if one sibling is using a substance the other sibling will be introduced and learn about the substance from them [121]. This is true for younger siblings because they look up to and model the behaviors of their older siblings [121,124] conducted a study to examine the drinking habits of parents, siblings, and friends to determine if the drinking habits of those the adolescent associated with had an effect on the drinking habits of adolescents.

Results from the study showed that age, sex, and previous use of alcohol contributed to regular alcohol use later in life. Parental alcohol use had a small effect on adolescent use but was persistent with positive associations. Sibling, co-twin, and friend use had a significant effect on alcohol use, but the friends' influence decreased over time. It is important to continue to examine the effects of family and friends on the behaviors of adolescents so that effective intervention strategies can be implements to mediated risk factors that can contribute to adolescent alcohol use. Admittedly, this case was worsened by the fact that our healthcare system is not adequately equipped to contain consequences of disorders emanating from drug abuse, leaving victims to degenerate into complete decadence and irreversible mental states. It is not surprising why the rate of depression and anxiety induced suicides is on the increase. As noted, this problem is not getting the attention it requires from both federal and state government, development partners [125] and our communities. In the past, it is a taboo to smoke marijuana popularly called "weed" in the public. But now, it is a trend and thing of pride among the adolescent.

Thus far, systemic consumption of drugs by adults makes them see nothing bad in adolescent drug abuse and the rate at which young criminals are paraded on the media i.e. television, radio, facebook, youtube etc, is alarming. Adolescent now have free access to dangerous weapons as much as they have to drugs, making the situation more dangerous. The era of "blue tongue", "purple tongue" and "red tongue" are now prominent with our youths consuming drugs freely at will. When cultism meets drugs, the result is that most rubbery gangs now consist of age group below 24 years particularly in yenagoa and its environs couple with previous and predominant crisis in the country given our population and energy $[1,3]$.

\section{Conclusion and Recommendation}

Substance use are growing public health problems particularly among the youth yet may be overlooked by health care providers. Since the dawn of the 21st century and 4th industrial revolution, several researchers have found that the use of substance use has become a threat multiplier, part of a modern society and a moderately customary part of late adolescent and young adult social life. However, substance use and/ or abuse in Yenagoa and its environs is no longer conjectural and exaggeration. The effect is real, complex and constantly changing in form and nature with serious adverse consequences. Generally, youths in rural areas especially in remote villages are vulnerable to misinformation and wrong company. Consequent to their curiosity, they fall into the hands of wrong people, drug addicts and people with low moral credibility. Therefore, all health care provider who care for adolescents and older adults must be alert for possible signs and symptoms of substance-use in their patients. Essentially, motivational interviewing should be emphasized upon, this is a structured, non-judgmental conversation in which the health care provider encourages the patient to examine his or her substance use and adopt a committed attitude toward changing their behavior.

Also, the Center for Substance Abuse Treatment recommends that screening for substance use including alcohol be part of the routine medical visit for all adolescents' persons between the age of 15 years and above. In addition, adolescent may lack awareness that their use of substances is problematic and might not bring it to the attention of the health care provider. Even close family members may miss problematic consumption by an adolescent relative whose drinking is occurring at home. Coexisting medical 
conditions, including cognitive impairment, can obscure signs of harmful use, which may be mistaken for anxiety, depression, or complications of current medical treatments. Research is needed to develop targeted screening methods and to identify the best treatment models for substance-use in adolescents. Treatment plans must encompass care for adolescents' patients with coexisting medical and psychiatric illnesses. New innovative models of care need to be created that allow for both coordination of services in integrated health care settings and treatment programs tailored for adolescents' patients.

Similarly, the fact that drug use is related to crime, cultist and militancy behaviours especially in the Niger Delta Region of Nigeria, the importance of mental health during the adolescent period is critical [1,3]. The knowledge about substance use and its devastating consequences should be highlighted. Tackling the underage substance abuse problem is indeed extremely complex, but it seems education and creation of green jobs for adolescents may play a key role [124]. Also, Nigeria may need to borrow a leaf from other countries with severe penalties against illicit drug peddling to check imminent catastrophe looming on the nation. This truth is bitter considering the consequences of the societal hazard as we are beginning to experience in yenagoa and its environs. Religious institutions should focus more on messages that can help revamp the society. Unfortunately, we have few organisations championing cause for prevention of drug abuse in the country, more is needed [125-132].

Moreover, prevention they say, is better and cheaper than cure. For those already addicted, there is need for various forms of restorative approach in the society. But the most potent solution is to break the chain. Drug addiction is preventable, and research has shown that preventive programmes that involve the family, schools, communities and the media, particularly the music industry are effective in reducing drug abuse [133-137]. It is necessary, therefore, to help adolescent and the general public to understand the risks of drug abuse and for teachers, parents and health care professionals to keep sending the message that drug addiction can be prevented if a person never abuse drugs. In addition, there is need for more severe laws both at the federal and state level to prevent drug abuse with tactical check on the inflow and free distribution of illicit drugs in our society.

Furthermore, adolescents should be helped to overcome their psychological problems so as to prevent entry into substance abuse. it seems that the Nigerian Government agencies particularly the National Drug Law Enforcement Agency (NDLEA), Niger Delta Development Commission (NDDC), Nigerian Content Development and Monitoring Board (NCDMB), Ministry of Niger Delta, Bayelsa State Ministry of Education and Bayelsa State Ministry of Health, Primary Health Care Board (i.e. Community and Family Health Department, adolescent's health desk etc) still has much work to do in terms of substance abuse prevention within the adolescent period. Since findings indicate that substance abuse begins at age 12-13, prevention programmes need to be implemented at an even younger age so as to highlight the public health risks involved.

\section{References}

1. Abdulraheem A FO, Olalekan R M, Abasiekong E M (2018) Mother and father adolescent relationships and substance use in the Niger delta: a case study of twenty-five (25) communities in Yenagoa local government of Bayelsa state, Nigeria. Sociol Int J 2(6): 541-548.

2. Abdulraheem Aishat Funmilayo (2019) Social Interaction between parents and adolescent's predisposition to substance use. A case study of Yenagoa local government, Bayelsa State, Nigeria. An Unpublished BSc thesis submitted to the department of sociology. Niger Delta University, Wilberforce Island, Gloryland Campus, Amassoma, Bayelsa State, Nigeria.

3. Funmilayo AA, Robert OT, Olalekan RM, Okoyen E, Tuebi M (2019) A study of the context of adolescent substance use and patterns of use in yenagoa local government, Bayelsa State, Nigeria. MOJ Addiction Medicine and Therapy 6(1): 25-32.

4. Merica D (2017) Trump declares opioid epidemic a national public health emergency. CNN.

5. Pretorius JWM (1998) Sociopedagogics 2000. Hatfield: JL Van Schaik publishers pp. 407.

6. Burger S, Gouws E, Kruger N (2000) The adolescent ( $2^{\text {nd }}$ edn). Heinemann Publishers (Pty) Ltd. Sandown, UK.

7. Madge N, Harvey JG (1999) Suicide among the young - the size of the problem. J Adolesc 22(1): 145-155.

8. National Drug Law Enforcement Agency (1997) Drug data collection and research, Lagos: Drug Demand Reduction Unit, National Drug Law Enforcement Agency.

9. Odejide AO (1997) Adolescent and young adult substance abuse in Nigeria. Center for health services, training, research and development, Status of Adolescents and Young Adults in Nigeria. Ibadan p.13.

10. Adelekan ML (1996) West African sub region: An overview of substance abuse problems. Drugs: Education, Prevention and Policy. 3(3): 231-237.

11. Onajole AT, Gbangbala AO (2004) Socio-dermographic characteristics of drug misuse in a polytechnic in Lagos, Nigeria. Nig. Jnl Health \& Biomed. Sciences 3(1): 40-43.

12. Young SE, Rhee SH, Stallings MC, Corley RP, Hewitt JK (2006) Genetic and environmental vulnerabilities underlying adolescent substance use and problem use: General or specific? Behav Genet 36(4): 603-615.

13. Zapert K, Snow DL, Tebes JC (2002) Patterns of substance use in early through late adolescence. Am J Community Psychol 30(6): 835-852.

14. US Department of Health and Human Services (2000) Healthy People 2010: Understanding and Improving Health, ( $2^{\text {nd }}$ edn) U.S. Government Printing Office, Washington, DC, USA.

15. Kelly KJ, Comello ML, Hunn LC (2002) Parent-adolescent communication, perceived sanctions against drug use, and youth drug involvement. Adolescence 37(148): 775-787.

16. Office of National Drug Control Policy (ONDCP) (2010) 2009 National Survey on Drug Use and Health Highlights.

17. Substance Abuse and Mental Health Services Administration (SAMHSA) (2010) The NSDUH Report: Trends in tobacco use among adolescents: 2002 to 2008.

18. Miller Day M, Dodd AH (2004) Toward a descriptive model of parentoffspring communication about alcohol and other drugs. Journal of Social and Personal Relationships 21(1): 69-91.

19. Weinberg NZ (2001) Risk factors for adolescent substance abuse. Journal of Learning Disabilities 34(4): 343-351.

20. Lin W, Dembo R (2008) An integrated model of juvenile drug use: A crossdemographic group study. Western Criminology Review 9(2): 3351.

21. Silberg J, Rutter M, D’Onofrio B, Eaves L (2003) Genetic and 
environmental risk factors in adolescent substance use. J Child Psychol Psychiatry 44(5): 664-676.

22. Hawkins JD, Oesterle S, Brown EC, Arthur MW, Abbott RD, et al. (2009) Results of a type 2 translational research trial to prevent adolescent drug use and delinquency. Arch Pediatr Adolesc Med 163(9): 789-798.

23. Hingson RW, Heeren T, Winter MR (2006) Age at drinking onset and alcohol dependence: age at onset, duration, and severity. Arch Pediatr Adolesc Med 160(7): 739-746.

24. Johnston LD, O'Malley PM, Bachman JG, Schulenberg JE (2007) Monitoring the Future, National Survey Results on Drug Use, 19752006. NIH Publication No. 07-6205, National Institute on Drug Abuse, Bethesda, MD, USA.

25. National Institute on Drug Abuse (NIDA) (2003) Marijuana Abuse (NIH Publication No. 02-3859, October 2002). Rockville, MD: Author.

26. Graydanus DE, Patel DR (2005) The adolescent and substance abuse: Current concepts. Curr Probl Pediatr Adolesc Health Care 35(3): 78-98.

27. Wright DR, Fitzpatrick KM (2004) Psychosocial correlates of substance use behaviors. Adolescence 39(156): 653-667.

28. Agrawal A, Lynskey MT (2006) The genetic epidemiology of cannabis use, abuse and dependence. Addiction 101(6): 801-812.

29. Gray KM (2007) Marijuana use, withdrawal, and craving in adolescents. Adolescent and Adolescent Psychiatry 57-65.

30. Johnston LD, O'Malley PM, Bachman JG, Schulenberg JE (2009) Monitoring the Futures: National Results Drug Use. Overview of Key Findings, 2008. NIH Publication No. 09-7401, National Institute on Drug Abuse, Bethesda, MD, USA.

31. Little M, Weaver SR, King KM, Liu F, Chassin L (2008) Historical change in the link between adolescent deviance proneness and marijuana use, 1979-2004. Prev Sci 9(1): 4-16.

32. Ellickson PL, Tucker JS, Klein DJ, Saner H (2004) Antecedents and outcomes of marijuana use initiation during adolescence. Prev Med 39(5): 976-984.

33. Fergusson DM, Horwood LJ, Lynskey MT, Madden PA (2003) Early reactions to cannabis predict later dependence. Arch Gen Psychiatry 60(10): 1033-1039.

34. Lessem JM, Hopfer CJ, Haberstick BC, Timberlake D, Ehringer MA, et al. (2006) Relationship between adolescent marijuana use and young adult illicit drug use. Behavior Genetics 36(4): 498-506.

35. Palmer RC, Young SE, Hopfer CJ, Corley RP, Stallings MC, et al. (2009) Developmental epidemiology of drug use and abuse in adolescence and young adulthood: Evidence of generalized risk. Drug Alcohol Depend 102(1-3): 78-87.

36. Patton GC, Coffey C, Lynskey MT, Reid S, Hemphill S, et al. (2007) Trajectories of adolescent alcohol and cannabis use into young adulthood. Addiction 102(4): 607-615.

37. Johnston LD, O’Malley PM, Bachman JG, Schulenberg JE (2008) Monitoring the Futures: National Results Drug Use. Overview of Key Findings, 2007. NIH Publication No. 08-6418, National Institute on Drug Abuse, Bethesda, MD, USA

38. Substance Abuse and Mental Health Services Administration (SAMHSA) (2006) Results From the 2005 National Survey on Drug Use and Health: National Findings.

39. Substance Abuse and Mental Health Services Administration (SAMHSA) (2008) Results From the 2007 National Survey on Drug Use and Health: National Findings. (Office of Applied Studies, NSDUH Series H-30, DHHS Publication No. SMA 06-4194).

40. Winters KC, Lee CS (2008) Likelihood of developing an alcohol and cannabis use disorder during youth: association with recent use and age. Drug Alcohol Depend 92(1-3): 239-247.
41. Hall WD (2006) Cannabis use and the mental health of young people. Aust N Z J Psychiatry 40(2): 105-113.

42. Patton GC, Coffey C, Carlin JB, Sawyer SM, Lynskey M (2005) Reverse gateways: Frequent cannabis use as a predictor of tobacco initiation and nicotine dependence. Addiction 100(10): 1518-1525.

43. Khiabani HZ, Bramness JG, Bjorneboe A, Morland J (2006) Relationship between THC concentration in blood and impairment in apprehended drivers. Traffic Injury Prevention 7(2): 111-116.

44. National Institute on Drug Abuse (NIDA) (2010) National School and Youth Trends.

45. Farhat T, Simons Morton B, Luk JW (2011) Psychosocial correlates of adolescent marijuana use; Variations by status of marijuana use. Addict Behav 36(4): 404-407.

46. Hampson SE, Andrews JA, Barckley M (2008) Adolescenthood predictors of adolescent marijuana use: Early sensation-seeking, deviant peer affiliation, and social images. Addictive Behaviors 33(9): 1140-1147.

47. Wittchen HU, Frohlich C, Behrendt S, Gunther A, Rehm J, et al. (2007) Cannabis use and cannabis use disorders and their relationship to mental disorders: A 10-year prospective-longitudinal community study in adolescents. Drug Alcohol Depend 88(1): S60-S70.

48. Caspi A, Roberts B W, Shiner R L (2005) Personality development: Stability and change. Annu Rev Psychol 56: 453-484.

49. Jones L, Bates G, Bellis M, Beynon C et al (2011) A summary of the health harms of drugs. London: Department of Health.

50. National Population Commission Abuja, Nigeria (2010) 2006 Housing population Census: Population on distribution by age and sex: State and Local Government Area, Priority able 4: 54-58.

51. Johnston LD, O’Malley PM, Bachman JG, Schulenberg JE (2010) Monitoring the Futures: National Results Drug Use. Overview of Key Findings, 2009. NIH Publication No. 10-7583, National Institute on Drug Abuse, Bethesda, MD, USA.

52. Tarter RE (2002) Etiology of adolescent substance use: a developmental perspective. Am J Addict 11(3): 171-191.

53. Choi NG, DiNitto DM, Marti CN (2017) Older adults who use or have used marijuana: help-seeking for marijuana and other substance use problems. J Subst Abuse Treat 77: 185-192.

54. Choi NG, DiNitto DM, Marti CN (2016) Older adult marijuana users and ex-users: comparisons of sociodemographic characteristics and mental and substance use disorders. Drug Alcohol Depend 165: 94-102.

55. Choi NG, DiNitto DM, Marti CN, Choi BY (2017) Association between nonmedical marijuana and pain reliever uses among individuals aged 50. J Psychoactive Drugs 49(4): 267-278.

56. Backinger C L, Fagan P, Matthews E, Grana R (2003) Adolescent and young adult tobacco prevention and cessation: current status and future directions. Tobacco Control 12(4): 46-53.

57. Foldes SS, An LC, Rode P, Schillo BA, Davern M, et al. (2010) The prevalence of Unrecognized Tobacco Use Among Young Adults. Am J Health Behav 34(3): 309-321.

58. Lemstra M, Bennett NR, Neudorf C, Kunts A, Nannapaneni U, et al. (2008) A Meta-analysis of marijuana and alcohol use by socio-economic status in adolescents Aged 10-15 Years. Can J Public Health 99(3): 172-177.

59. Oshikoya KA, Alli A (2006) Perception of Drug Abuse Amongst Nigerian Undergraduates. World Journal of Medical Sciences 1(2): 133-139.

60. Tomar SL, Fox BJ, Severson HH (2009) Is smokeless tobacco use an appropriate public health strategy for reducing societal harm from cigarette smoking? Int J Environ Res Public Health 6(1): 10-24.

61. Centers for Disease Control (CDC) (2009) State-specific smokingattributable mortality and years of potential life lost-United States, 2000-2004. Morbidity Mortality Weekly Report 58(2): 29-33. 
62. Pozzato G, Moretti M, Franzin F, Crocè LS, Lacchin T, et al. (1995) Ethano metabolism and aging: the role of "first pass metabolism" and gastric alcohol dehydrogenase activity. J Gerontol A Biol Sci Med Sci 50(3): B135-B141.

63. Audrain McGovern J, Rodriguez D, Tercyak K P, Cuevas J, Rodgers K, et al. (2004) Identifying and characterizing adolescent smoking trajectories. Cancer Epidemiol Biomarkers Prev 13(12): 2023-2034.

64. Ubom IU (2004) Behaviour problems of children: Counselling interventions. Nigerian Society for Educational Psychologists (NISEP). p. 47-58.

65. Abroms L, Simons Morton B, Haynie DL, Chen R (2005) Psychological predictors of smoking trajectories during middle and high school. Addiction 100(6): 852-861.

66. Bernat D H, Erickson D J, Windome R, Perry C L, Forster J L (2008) Adolescent smoking trajectories: Results from a population-based cohort study. J Adolesc Health 43(4): 334-340.

67. Substance abuse and mental health services administration (1996) Preliminary estimates from the 1995 National Household Survey on Drug Abuse. Advance Report Number 18. Rockville, MD, USA.

68. Gilman SE, Rende R, Boerger J, Abrams DB, Buka SL et al. (2008) Parental smoking and adolescent smoking initiation: An intergenerational perspective on Tobacco Control. Pediatrics 123(2): e274-e281.

69. Idowu A (1987) Prevalence of smoking and drug abuse among students in Ilorin metropolis: Implications for Counselling. Journal of Education 7: 85-97.

70. Okorodudu R, Okorodudu GN (2004). An overview of conduct problems of the Nigerian child. Journal of the Nigerian Society for Educational Psychologists. (NICEP) p. 76-83.

71. Enakpoya E (2009) Prevalence of drug abuse among Nigerian adolescents: Implication for counselling. The Counsellor 26: 2 .

72. Kobiowu SV (2006) The social and academic implications of drug abuse among undergraduates: A case study of the Obafemi Awolowo University Ile-Ife, Nigeria. International Journal of Psychosocial Rehabilitation. 11(1): 61-68.

73. Komro KA, Perry CL, Veblen Mortenson S, Farbakhsh K, Toomey TL, et al. (2008) Outcomes from randomized controlled trial of a multicomponent alcohol use preventive intervention for urban youth: Project Northland Chicago. Addiction 103(4): 606-618.

74. Grant BF, Chou SP, Saha TD, Pickering RP, Kerridge BT, et al. (2017) Prevalence of 12-month alcohol use, high risk drinking, and DSM-IV alcohol use disorder in the United States, 2001-2002 to 2012-2013: results from the National Epidemiologic Survey on Alcohol and Related Conditions. JAMA Psychiatry 74(9): 911-23.

75. Han BH, Moore AA, Sherman S, Keyes KM, Palamar JJ (2017) Demographic trends of binge alcohol use and alcohol use disorders among older adults in the United States, 2005-2014. Drug Alcohol Depend 170: 198-207.

76. National Survey on Drug Use and Health (NSDUH) (2014) Online Available: https://www.datafiles.samhsa.gov/study/national-surveydrug-use-and-health-nsduh-2014-nid13618 [June 11, 2019].

77. Brown S A, McGue M, Maggs J, Schulenberg J, Hingson R, et al. (2008) A developmetal perspective on alcohol and youths 16 to 20 years of age. Pediatrics 121(4): S290-S310.

78. Merline A, Jager J, Schulenberg JE (2008) Adolescent risk factors for adult alcohol use and abuse: stability and change of predictive value across early and middle adulthood. Addiction 103(1): 84-99.

79. Johnston LD, O'Malley PM, Bachman JG, Schulenberg JE (2006) Monitoring the Future, National Survey Results on Drug Use, 1975-2005. 1: Secondary School Students.

80. Substance Abuse and Mental Health Services Administration (SAMHSA) (2009). The NSDUH Report: Trends in tobacco use among adolescents: 2002 to 2009.
81. Ellickson P L, Tucker J S, Klein D J, McGuigan K (2001) Prospective risk factors for alcohol misuse in late adolescence. J Stud Alcohol 62(6): 773782.

82. Office of the Surgeon General (2007) The Surgeon General's call to action to prevent and reduce underage drinking. Rockville, MD: Department of Health and Human Services.

83. Patrick ME, Schulenberg JE (2010) Alcohol use and heavy episodic drinking prevalence and predictors among national samples of american eight- and tenthgrade students. J Stud Alcohol Drugs 71(1): 41-45.

84. National Institute on Alcohol Abuse and Alcoholism (NIAAA) (2000).

85. Kaplan HI, Sadock BJ (2003) Synopsis of psychiatry. Williams and Wilkins, USA.

86. Degenhardt L, Hall W, Linskey M (2001) Alcohol, cannabis and tobacco use among Australians: a comparison of the associations with other drug use and use disorders, affective and anxiety disorders and psychosis. Addiction 96(11): 1603-1614.

87. Vestal RE, McGuire EA, Tobin JD, Andres R, Norris AH, et al. (1977) Aging and ethanol metabolism. Clin Pharmacol Ther 21(3): 343-354.

88. Wadd S, Papadopoulos C (2014) Drinking behaviour and alcohol-related harm amongst older adults: analysis of existing UK datasets. BMC Res Notes 7: 741

89. Mowbray O, Washington T, Purser G, O'Shields J (2017) Problem drinking and depression in older adults with multiple chronic health conditions. J Am Geriatr Soc 65(1): 146-152.

90.Zanjani F, Hoogland AI, Downer BG (2013) Alcohol and prescription drug safety in older adults. Drug Healthc Patient Saf 5: 13-27.

91. Cousins G, Galvin R, Flood M, Kennedy MC, Motterlini N, et al. (2014) Potential for alcohol and drug interactions in older adults: evidence from the Irish Longitudinal Study on Ageing. BMC Geriatr 14: 57.

92. Ifabumuyi 0 (1986) Alcohol and drug addiction in Northern Nigeria. Acta Psychiatr Scand 73(5): 479-480.

93. Pela OA (1989) Patterns of Adolescent Psychoactive Substance Abuse in Benin City, Nigeria. Adolescence 24(95): 569-574.

94. Orlando M, Tucker JS, Ellickson, PL, Klein DJ (2004) Developmental trajectories of cigarette smoking and their correlates from early adolescence to young adulthood. J Consult Clin Psychol 72(3): 400-410.

95. National Survey on Drug Use and Health (NSDUH) (2010) Online Available: https://www.datafiles.samhsa.gov/study-dataset/nationalsurvey-drug-use-and-health-2010-nsduh-2010-ds0 [May 21, 2019].

96. Esen AJA (1997) Discipline in schools. Journal of the Cross River, Educator 1(1): 40.

97. Obiamaka VO (2004) Problem behaviours in Nigerian secondary schools. Nigeria Society for Education Psychologists (NISEP), p. 69-75.

98. Fayombo GA, Aremu S (2004) Drug education and its effects on the educational performance of some adolescent's drug abusers in Ibadan. The Counse.

99. Adesanya A, Ohaeri J U, Ogunlesi A O, Adamson T A, Dejide O A et al. (1997) Psychoactive substance abuse among inmates of a Nigerian prison population. Drug Alcohol Depend 47(1): 39-44.

100. Ekpo AU (1981) Marijuana is very harmful. Nigerian Gong p. 9-11.

101. Olatunde A (1997) Self-medication: Benefits, precautions and dangers, The Macmillan Press, London.

102. Okuh B (1998) Problems of secondary school learners. Careers 2: 3.

103. Oduaran D (1999) Psychological guidance of the school child. Ibadan, Evans Books.

104. Johnson MP (1999) Power Relaxations and affective style as determinants on confidence in impression formation in a game situation. Journal of Experimental Social Psychology 7: 98-100. 
105. Atoyebi OA, Atoyebi OE (2013) Pattern of Substance Abuse among Senior Secondary School Students in a Southwestern Nigerian City. International Review of Social Sciences and Humanities 4(2): 54-65

106. Gullota TP, Adams GR, Montemayor R (1995) (Eds.) Substance misuse in adolescence. London: Sage Publications.

107. National Institute on Drug Abuse (NIDA) (2009) Teen methamphetamine use, cigarette smoking at lowest levels in NIDA's 2009 Monitoring the Future Survey.

108. Ulrich TR (2010) Prevalence of substance abuse in the adolescent population. US Pharm 35(3): 31-37.

109. Boyd M, Howard J, Zucker R (Eds.) (1995) Alcohol problems among adolescents. Hove: Lawrence Erlbaum Associates Publishers.

110. Beman D S (1995) Risk factors leading to adolescent substance abuse. Adolescence30(117): 200-208.

111. Parry CDH, Meyers B, Morojele NK, Flisher AJ, Bhana A, et al. (2004) Trends in adolescent alcohol and other drug use: findings from three sentinel sites in South Africa (1997-2001). J Adolesc 27(4): 429-440.

112. Okonkwo CC, Lawal R, Ojo M, Eze C, Ladapo HT, et al. (2010) Substance Use among Students in a Public Senior Secondary School in Lagos. National Institute on Drug Abuse. United States Department of Health Publication p. 8-10.

113. Essien C F (2010) Drug Use And abuse among Students In tertiary institutions---The Case of Federal University of Technology, Minna Journal of Research in National Development 8(1): 30-35.

114. McQueen A, Getz JG, Bray JH (2003) Acculturation, substance use, and deviant behavior: Examining Separation and family conflict as mediators. Child Dev 74(6): 1737-1750.

115. Kaplow JB, Curran PJ, Dodge KA \& The Conduct Problems Prevention Research Group (2002) Child, parent, and peer predictors of earlyonset substance use: A multisite longitudinal study. J Abnorm Child Psychol 30(3): 199-216.

116. Oxford ML, Harachi TW, Catalano RF, Abbott RD (2000) Preadolescent predictors of substance initiation: A test of both the direct and mediated effect of family social control factors on deviant peer associations and substance initiation. Am J Drug Alcohol Abuse 27(4): 599-616.

117. Simons Morton B, Chen RS (2006) Over time relationships between early adolescent and peer substance use. Addict Behav 31(7): 12111223.

118. Miller TQ Volk RJ (2002) Family relationships and adolescent cigarette smoking: Results from a national longitudinal survey. Journal of Drug Issues 32(3): 945-972.

119. Beitchman J H, Adlaf E M, Atkinson L, Douglas L, Massak A, (2005) Psychiatric and substance use disorders in late adolescence: The role of risk and perceived social support. Am J Addict 14(2): 124-138.

120. Brook JS, Brook D W, Arencibia Mireles O, Richter L, Whiteman M (2001) Risk factors of adolescent marijuana use across cultures and across time. The Journal of Genetic Psychology 162(3); 357-374.
121. Bahr S J, Hoffmann J P, Yang X (2005) Parental and peer influences on the risk of adolescent drug use J Prim Prev 26(6): 529-551.

122. Duan L, Chou C, Andreeva VA, Pentz MA (2008) Trajectories of peer social influences as long-term predictors of drug use from early through late adolescence. J Youth Adolesc 38: 454-465.

123. Vakalahi HF (2001) Adolescent substance use and family-based risk and protective factors: A literature review. J Drug Educ 31(1): 29-46.

124. Raimi Morufu Olalekan, Raimi Aziba anyam Gift, Raimi Mariam Oluwakemi (2019) How Universities Can Create Green Jobs for Students. Peer Res Nest 1(2).

125. Chassin L, Handley ED (2006) Parents and families as contexts for the development of substance use and substance use disorders. Psychol Addict Behav 20(2): 135-137.

126. Hasin DS, Saha TD, Kerridge BT, Goldstein RB, Chou SP, et al. (2015) Prevalence of marijuana use disorders in the United States between 2001-2002 and 2012-2013. JAMA Psychiatry 72(12): 1235-1242.

127. Lantz PM (2003) Smoking on the rise among young adults: implications for research and policy. Tob Control12 (1): i60-i70.

128. McEvoy LK, Kritz Silverstein D, Barrett Connor E, Bergstrom J, Laughlin GA (2013) Changes in alcohol intake and their relationship with health status over a 24-year follow-up period in community-dwelling older adults. J Am Geriatr Soc 61(8): 1303-1308.

129. National Drug Law Enforcement Agency (2014) Annual Report. FGN: NDLEA.

130. National Population Commission (2006) Bayelsa State, Yenagoa LGA.

131. Office of National Drug Control Policy (ONDCP) (2010) 2009 National Survey on Drug Use and Health Highlights.

132. Olalekan RM, Omidiji AO, Williams EA, Christianah MB, Modupe O (2019) The roles of all tiers of government and development partners in environmental conservation of natural resource: a case study in Nigeria. MOJ Ecology \& Environmental Sciences 4(3):1 14-121.

133. Poelen EA, Scholte RH, Willemsen G, Boomsma DI, Engels R (2007) Drinking by parents, siblings, and friends as predictors of regular alcohol use in adolescents and youth adults: A longitudinal twin-family study. Alcohol Alcohol 42(4): 362-369.

134. Pollard MS, Tucker JS, Green HD, Kennedy D, Go M (2010) Friendship networks and trajectories of adolescent tobacco use. Addict Behav 35(7): 678-685.

135. Rodu B, Cole P (2010) Evidence against a gateway from smokeless tobacco use to smoking. Nicotine Tob Res 12(5): 530-534.

136. Soldz S, Cui X (2002) Pathways through adolescent smoking: A 7-year longitudinal grouping analysis. Health Psychology 21(5): 495-504.

137. Thomas JL, Renner CC, Patten CA, Decker PA, Utermohle CJ, et al. (2010) Prevalence and correlates of tobacco use among middle and high school students in western Alaska. International Journal of Circumpolar Health 69(2): 168-180. 